\title{
El Clima en Texcoco
}

Vol. 1, No. 12. Diciembre 2019

www.grandmendmexico.mx/clima DOI: https://doi.org/10.35243/ect19.01

\section{REPORTE DE VARIABLES AMBIENTALES REGISTRADAS EN LA ESTACIÓN METEOROLÓGICA GRAND MEND MÉXICO DEL MES DE DICIEMBRE DEL 2019}

Hernández-Mendieta, Ernesto y Rubio-Granados, Catalina

Grand Mend México, S.A. de C.V. Netzahualcóyotl 214. Piso 3, Oficina 6-A. Col. Centro. 56100.

Texcoco, Estado de México. México. Tel. +52 595955 8379; E-mail: grandmend.mexico@gmail.com

Publicación en línea: Enero 19, 2020

DOI: https://doi.org/10.35243/ect19.01.12

ESTACIÓN METEOROLÓGICA GRAND MEND MÉXICO

$19^{\circ}$ 29' 17.62" N; 98 51' 57.28” O; Alt: 2298 msnm

Inicio de Operaciones: Enero 4 del 2019

DICIEMBRE 2019

\begin{tabular}{|c|c|c|c|c|c|c|c|c|}
\hline & \multicolumn{3}{|c|}{ Temperatura $\left({ }^{\circ} \mathrm{C}\right)$} & & \multicolumn{2}{|c|}{ Vel. Viento $(\mathrm{km} / \mathrm{h})$} & & \\
\hline Día & Media & Máx. & Min. & $\% \mathrm{HR}$ & Media & Máx. & Barómetro & Pres (mm) \\
\hline 1 & 15.80 & 25.00 & 8.10 & 60.68 & 6.86 & 41.80 & 1026.45 & 0.00 \\
\hline 2 & 14.07 & 22.10 & 7.60 & 73.42 & 2.83 & 19.30 & 1029.33 & 0.00 \\
\hline 3 & 15.11 & 23.40 & 7.80 & 59.37 & 3.49 & 24.10 & 1027.42 & 0.00 \\
\hline 4 & 14.76 & 23.30 & 6.60 & 55.02 & 3.38 & 25.70 & 1026.82 & 0.00 \\
\hline 5 & 14.45 & 22.90 & 6.10 & 53.07 & 2.49 & 4.80 & 1027.40 & 0.00 \\
\hline 6 & 14.47 & 24.80 & 6.20 & 43.08 & 5.49 & 35.40 & 1028.94 & 0.00 \\
\hline 7 & 12.18 & 21.90 & 3.70 & 55.58 & 2.02 & 16.10 & 1031.19 & 0.00 \\
\hline 8 & 14.09 & 23.50 & 5.50 & 54.38 & 1.71 & 19.30 & 1028.12 & 0.00 \\
\hline 9 & 15.03 & 24.10 & 6.40 & 50.38 & 4.38 & 32.20 & 1025.70 & 0.00 \\
\hline 10 & 14.90 & 24.20 & 7.60 & 57.80 & 3.99 & 30.60 & 1026.16 & 0.00 \\
\hline 11 & 13.24 & 21.20 & 7.70 & 70.80 & 3.62 & 30.60 & 1029.09 & 0.00 \\
\hline 12 & 13.61 & 22.60 & 6.20 & 64.11 & 2.83 & 20.90 & 1029.27 & 0.00 \\
\hline 13 & 14.59 & 22.20 & 7.50 & 53.92 & 3.00 & 20.90 & 1026.97 & 0.00 \\
\hline 14 & 13.80 & 22.80 & 5.90 & 49.13 & 2.64 & 19.30 & 1025.69 & 0.00 \\
\hline 15 & 14.26 & 22.80 & 6.30 & 48.07 & 4.99 & 29.00 & 1025.23 & 0.00 \\
\hline 16 & 14.18 & 21.90 & 6.80 & 52.40 & 5.54 & 37.00 & 1024.79 & 0.00 \\
\hline 17 & 13.97 & 21.70 & 7.30 & 63.33 & 4.55 & 32.20 & 1024.96 & 0.00 \\
\hline 18 & 9.88 & 18.40 & 5.20 & 76.93 & 3.54 & 20.90 & 1026.54 & 0.00 \\
\hline 19 & 10.65 & 20.40 & 2.90 & 70.99 & 2.77 & 25.70 & 1026.76 & 0.00 \\
\hline 20 & 12.67 & 19.50 & 7.20 & 61.79 & 1.87 & 12.90 & 1027.31 & 0.00 \\
\hline 21 & 12.58 & 19.50 & 8.10 & 69.63 & 3.21 & 30.60 & 1026.98 & 0.00 \\
\hline 22 & 10.08 & 13.70 & 7.00 & 80.92 & 1.97 & 17.70 & 1028.88 & 0.00 \\
\hline 23 & 13.07 & 21.20 & 5.40 & 64.45 & 1.65 & 22.50 & 1027.53 & 0.00 \\
\hline 24 & 13.68 & 21.20 & 5.90 & 58.19 & 2.57 & 22.50 & 1026.19 & 0.00 \\
\hline 25 & 13.60 & 21.40 & 6.90 & 51.42 & 2.13 & 20.90 & 1024.31 & 0.00 \\
\hline 26 & 13.81 & 22.10 & 5.50 & 54.79 & 2.42 & 20.90 & 1024.81 & 0.00 \\
\hline 27 & 14.81 & 23.20 & 7.40 & 57.92 & 3.99 & 32.20 & 1024.80 & 0.00 \\
\hline 28 & 15.13 & 22.40 & 7.90 & 63.33 & 5.54 & 37.00 & 1024.31 & 0.00 \\
\hline 29 & 14.44 & 21.10 & 7.40 & 57.24 & 4.39 & 32.20 & 1024.85 & 0.00 \\
\hline 30 & 15.58 & 22.10 & 8.40 & 55.67 & 7.11 & 40.20 & 1024.70 & 0.00 \\
\hline 31 & 15.19 & 23.70 & 7.10 & 59.28 & 3.11 & 29.00 & 1026.15 & 0.00 \\
\hline Media & 13.80 & 21.95 & 6.63 & 59.58 & 3.55 & 25.95 & 1026.70 & $0.00 *$ \\
\hline
\end{tabular}

*Valor Acumulado Mensual 
ESTACIÓN METEOROLÓGICA GRAND MEND MÉXICO

$19^{\circ} 29^{\prime} 17.62$ " N; 98 51' 57.28" O; Alt: 2298 msnm

Inicio de Operaciones: Enero 4 del 2019

DICIEMBRE 2019
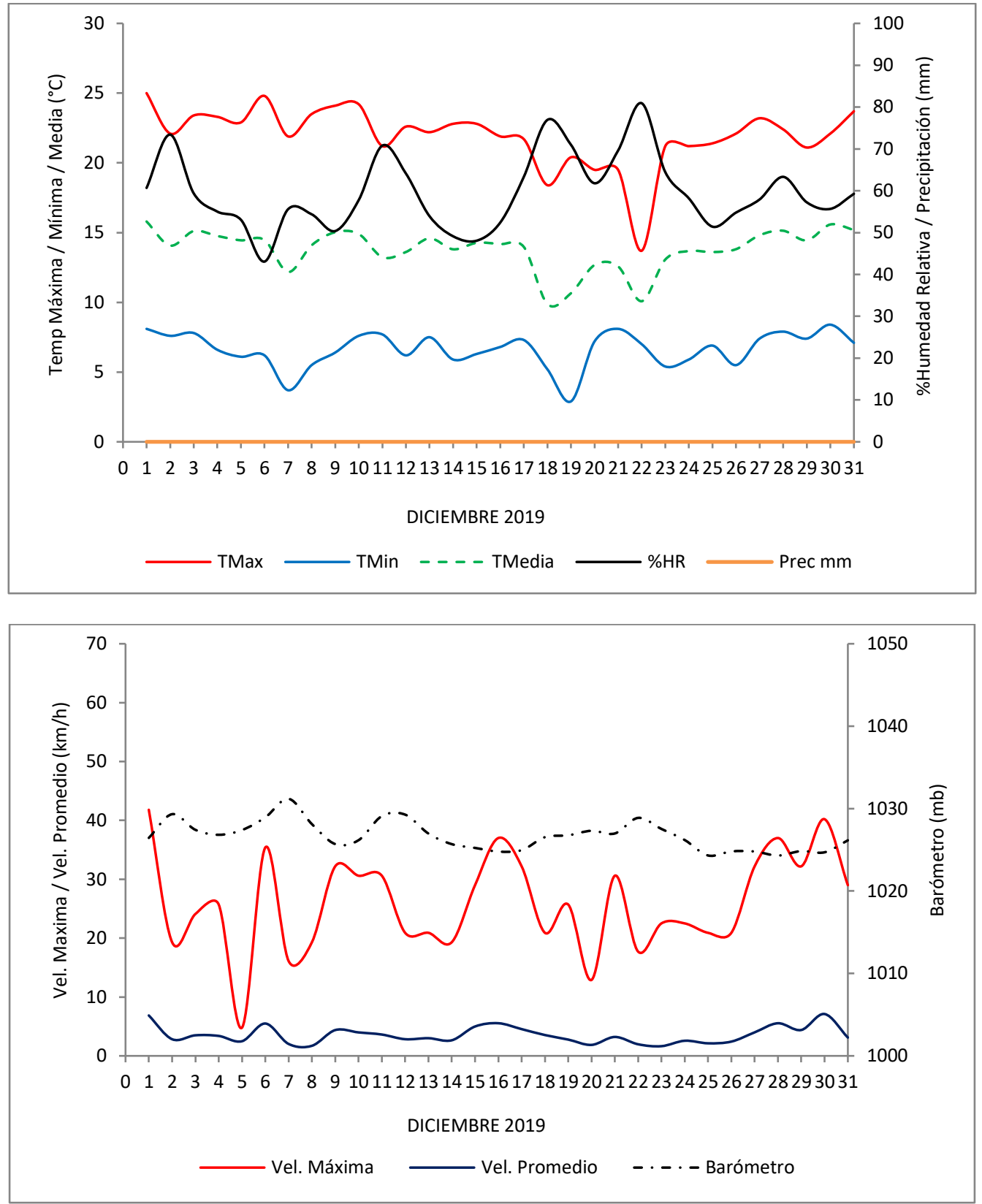